\title{
Antitussive Effect of Fritillaria unibracteata Hsiao et K. C. Hsia.
}

\author{
Jung-Wook Moon, Chen-Zhi and Won-Seob Song ${ }^{1}$ * \\ College of Life and Geographical Sciences, Qinghai Normal University, Xining 810008, China \\ ${ }^{1}$ College of Life Science and Natural Resources, Sunchon National University, Suncheon 540-742, Korea
}

\begin{abstract}
This experiment was conducted to clarify the antitussive effect of Fritillaria unibracteata Hsiao et K. C. Hsia. The antitussive effect in ethanol $(75,50,30 \%)$ extracts from $F$. unibracteata was relatively high. The ethanol extracts of 20 , $40 \mathrm{mg} / \mathrm{kg}$ concentrations were especially good antitussive effect. The ethanol extracts of $F$. unibracteata showed lower antitussive activities of $20 \sim 30 \%$ than sodium chloride injection used as a blank space control.
\end{abstract}

Key words - Fritillaria unibracteata Hsiao et K. C. Hsia, Antitussive effect

\section{Introduction}

The Fritillaria in Liliaceae is a major source of Chinese medicine. It exist about 130 species all over the world, and mainly distributed in the Northern Hemisphere temperate zone (Lis et al., 2001; Hua et al., 2003; Lin et al., 2001). Its pharmacodynamic is the antitussive effects, expectorant effects, asthma, anti-bacterial effects, sedation, analgesia, cardiovascular function (Hua et al., 2005), anti-ulcer effect (Cao et al., 2009), anti-platelet aggregation (Xiao et al., 2007) and anti-tumor effect (Wang et al., 2002).

In recent years, researches on cough medicine are paid closely attention, and the pathway of antitussive properties (Chao and Hu, 1993), mechanism and screening methods are widely discussed by domestic and foreign scholars (Pi and Wu, 2004). The chemical composition of Fritillaria plant is alkaloids and non-alkaloid section, in which alkaloids section is the main part of the activity. F. unibracteata is used in single herb or compound traditional medicine for the cough treatment (Zhou et al., 2006; Chen et al., 2007), because $F$. unibracteata is one of the highest Fritillaria species on acquisition volume, especially, and the expectorant, antitussive and other physiological activity are slightly stronger than others ( $\mathrm{Li}, 1995)$. Concerning antitussive effect study on $F$. unibracteata, it is found that there has been no research on $F$. unibracteata cultivated in the Qinghai-Tibet Plateau (Gao et

${ }^{*}$ Corresponding author. E-mail : chinakor@empas.com al., 2000). Therefore, this article takes the $F$. unibracteata cultivated in the ecological environment of Qinghai-Tibet Plateau as an experimental material, adopting the Ammonia Citation Cough Method in mice (Zhang et al., 2007) to determine the antitussive effect of its ethanol extract.

\section{Materials and Methods}

\section{Plant material}

Fritillaria unibracteata is supplied by Prof. Chen Zhi of China-Korea Plateau Wild Flower Institute. Male and female mice were purchased from Qinghai Biology Research Institute at 18 22 g weighing.

\section{Extraction}

Firstly, crush the dry $F$. unibracteata for $500 \mathrm{~g}$. Then extract with $75 \%, 50 \%, 30 \%$ ethanol solvent $(2,000 \mathrm{~mL})$. There are 4 times of extraction totally, each lasts 4 hours with extraction temperature of $60^{\circ} \mathrm{C}$, and the crude concentrated extract is evaporated to obtain at $45^{\circ} \mathrm{C} \sim 50^{\circ} \mathrm{C}$ by Rotary evaporator. Average yield is $5.28 \%$, and then the crude extracts are prepared to $F$. unibracteata suspension with different concentrations. Concentrations are $10,20,40 \mathrm{mg} / \mathrm{kg}$ respectively.

\section{The control group}

Codeine phosphate with effective antitussive effect is selected as the positive control group, a dose of $25 \mathrm{mg} / \mathrm{kg}$. $0.9 \%$ sodium chloride injection as the blank control group. 
Korean J. Plant Res. 24(6) : 729 732 (2011)

Table 1. Medicine of controlled conditions.

\begin{tabular}{lc}
\hline \hline Division & Control medicine \\
\hline Positive control & Codeine Phosphate $(25 \mathrm{mg} / \mathrm{Kg})$ \\
Blank space control & Sodium chloride injection $0.9 \%$ \\
$(25 \mathrm{mg} / \mathrm{kg})$
\end{tabular}

The positive control group and blank control group of $F$. unibracteata extract are shown in Table 1.

\section{Ammonia coughs method in mice}

Ammonia coughs method is executed by Zhang et al. (2007). Mice are randomly divided into groups of 10 each (male and female in half). Investigational medicine is set into high, medium and low dose group, respectively 10, 20, $40 \mathrm{mg} / \mathrm{kg}$, and suspended with solution of $0.9 \%$ sodium chloride. Positive control group receives same solvent (25 $\mathrm{mg} / \mathrm{kg}$ ); the above groups receive the medicine of irrigation stomach for 5 days, once a day. Mice are placed in an inverted beaker under which $0.15 \mathrm{ml}$ concentrated ammonia (25.0 $28.0 \%$ ) in the Heating bath is evaporated; when ammonia steam stimulation to mice within the scheduled time, the mice are quickly transferred to a large beaker, then the cough times of mice in 3 minutes are recorded. Occurring 3 times cough and more within 1 minute is typical known as "cough", less than 3 times as "no cough". The cough is subject to abdominal severe contraction and mouth sound (with stethoscope) on mice.

\section{Determination on antitussive effect of $\boldsymbol{F}$. unibracteata}

Mice are randomly divided into groups of 10 each (male and female in half). Ammonia cough method in mice (Zhang et al., 2007) is used in experiments, the above-mentioned groups receive the irrigation stomach for 3 different doses $(10,20,40 \mathrm{mg} / \mathrm{kg})$ of ethanol extracts of $F$. unibracteata with $75,50,30$; the control group receives the medicine (codeine phosphate, sodium chloride injection $0.9 \%$ ) dose of $25 \mathrm{mg} / \mathrm{kg}$. The groups are given medicine of irrigation stomach once a day, for 5 days, and the experiment is on the sixth day.

\section{Results and Discussion}

The antitussive experiment in $75 \%$ ethanol extract of $F$. unibracteata, $10,20,40 \mathrm{mg} / \mathrm{kg}$ dose and the positive control
Table 2. Effect of F. unibracteata $75 \%$ ethanol extracts on incubation period of cough by ammonia liquor in mice $(n=10)$.

\begin{tabular}{lcc}
\hline \hline Solvent & $\begin{array}{c}\text { Dose } \\
(\mathrm{mg} / \mathrm{kg})\end{array}$ & $\begin{array}{c}\text { Incubation period } \\
\text { of cough/s }\end{array}$ \\
\hline Ethanol extracts $^{1)}\langle\mathrm{I} 》$ & $10 \mathrm{mg}$ & $18.3 \pm 3.4$ \\
Ethanol extracts $^{1)}\langle\Pi \rrbracket$ & $20 \mathrm{mg}$ & $25.3 \pm 5.7$ \\
Ethanol extracts $^{1)}\langle[\Pi \Pi 》$ & $40 \mathrm{mg}$ & $26.6 \pm 5.2$ \\
Codeine Phosphate $^{2)}$ & $25 \mathrm{mg}$ & $20.6 \pm 2.4$ \\
Sodium chloride injection $^{3)}$ & $25 \mathrm{mg}$ & $14.3 \pm 3.6$
\end{tabular}

${ }^{1)}$ Ethanol extracts, ${ }^{2)}$ Positive control, ${ }^{3)}$ Blank space control

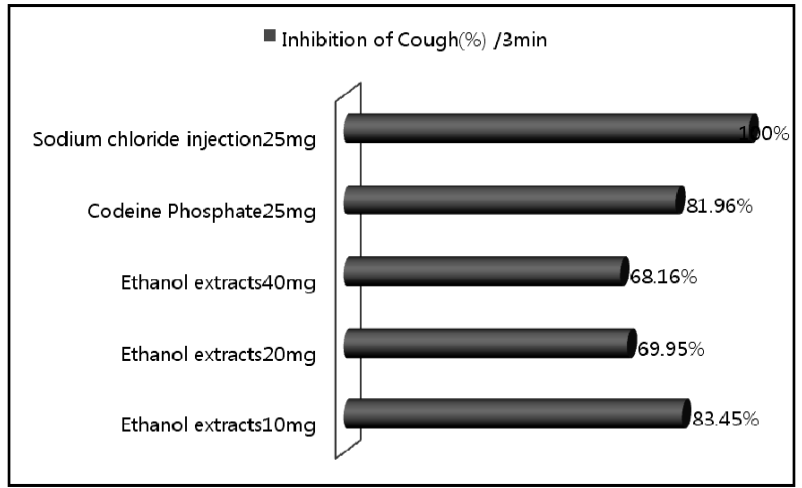

Fig. 1. F. unibracteata $75 \%$ ethanol extracts on cough induced by ammonia liquor in mice controlled conditions.

group (25 mg/kg, codeine phosphate) on arousing cough inhibition in mice are $16.55 \%, 30.05 \%, 31.84 \%, 18.04 \%$ respectively; the antitussive experiment in $50 \%$ ethanol extract of $F$. unibracteata, 10, 20, $40 \mathrm{mg} / \mathrm{kg}$ dose on arousing cough inhibition in mice are $17.03 \%, 29.89 \%, 32.95 \%$ with antitussive effects; the antitussive experiment in $30 \%$ ethanol extract of F. unibracteata, 10, 20, $40 \mathrm{mg} / \mathrm{kg}$ dose on arousing cough inhibition in mice are $14.56 \%, 24.72 \%, 26.55 \%$ with good antitussive effect. The antitussive effect of $F$. unibracteata ethanol extract is shown in Table 2, 3, 4 and Figure 1, 2, 3.

F. unibracteata ethanol extract of $10,20,40 \mathrm{mg} / \mathrm{kg}$ dose has a significant antitussive effect to mice in ammonia liquor, especially high, middle dose group with obvious antitussive effects. Middle and high doses of $F$. unibracteata ethanol extract is better than the positive control group (codeine phosphate) on antitussive effect. The experimental results show that the ethanol extracts of $F$. unibracteata has the antitussive effect. 
Table 3. Effect of $F$. unibracteata $50 \%$ ethanol extracts on incubation period of cough by ammonia liquor in mice $(\mathrm{n}=10)$.

\begin{tabular}{|c|c|c|}
\hline Solvent & Dose $(\mathrm{mg} / \mathrm{kg})$ & Incubation period of cough/s \\
\hline Ethanol extracts $^{1)}\langle I\rangle$ & $10 \mathrm{mg}$ & $17.7 \pm 4.2$ \\
\hline Ethanol extracts ${ }^{1)}\langle\Pi \rrbracket$ & $20 \mathrm{mg}$ & $24.7 \pm 7.6$ \\
\hline Ethanol extracts ${ }^{1)}\langle[\Pi \Pi\rangle$ & $40 \mathrm{mg}$ & $27.1 \pm 5.4$ \\
\hline Codeine Phosphate ${ }^{2)}$ & $25 \mathrm{mg}$ & $20.6 \pm 2.4$ \\
\hline Sodium chloride injection ${ }^{3)}$ & $25 \mathrm{mg}$ & $14.3 \pm 3.6$ \\
\hline
\end{tabular}

${ }^{1)}$ Ethanol extracts, ${ }^{2)}$ Positive control, ${ }^{3)}$ Blank space control

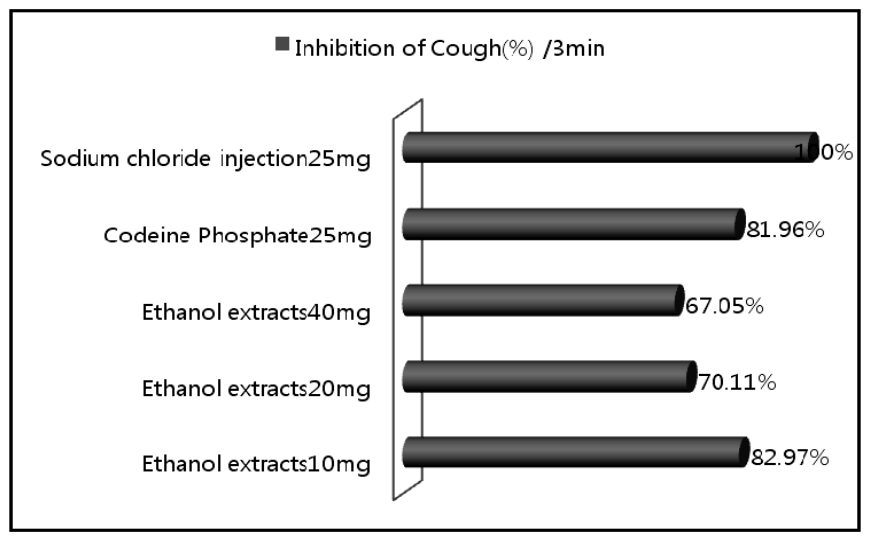

Fig. 2. F. unibracteata 50\% ethanol extracts on cough induced by ammonia liquor in mice controlled conditions.

Table 4. Effect of $F$. unibracteata $30 \%$ ethanol extracts on incubation period of cough by ammonia liquor in mice $(\mathrm{n}=10)$.

\begin{tabular}{|c|c|c|}
\hline Solvent & Dose $(\mathrm{mg} / \mathrm{kg})$ & Incubation period of cough/s \\
\hline Ethanol extracts $^{1)}\langle I\rangle$ & $10 \mathrm{mg}$ & $16.2 \pm 3.4$ \\
\hline Ethanol extracts ${ }^{1)}\langle\Pi \rrbracket$ & $20 \mathrm{mg}$ & $20.8 \pm 5.7$ \\
\hline Ethanol extracts ${ }^{1)}\langle[\Pi \rrbracket\rangle$ & $40 \mathrm{mg}$ & $22.1 \pm 5.2$ \\
\hline Codeine Phosphate ${ }^{2)}$ & $25 \mathrm{mg}$ & $20.6 \pm 2.4$ \\
\hline Sodium chloride injection ${ }^{3)}$ & $25 \mathrm{mg}$ & $14.3 \pm 3.6$ \\
\hline
\end{tabular}

${ }^{1)}$ Ethanol extracts, ${ }^{2)}$ Positive control, ${ }^{3)}$ Blank space control

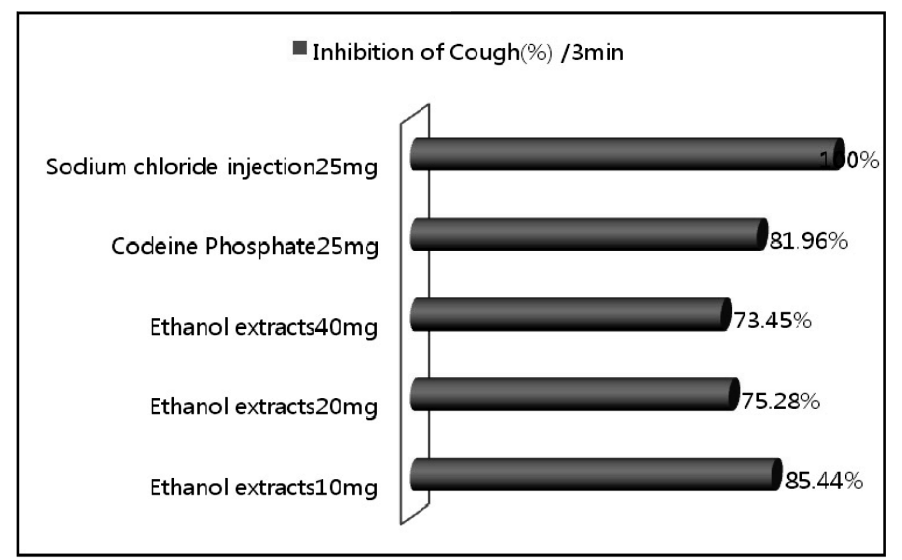

Fig. 3. F. unibracteata $30 \%$ ethanol extracts on cough induced by ammonia liquor in mice controlled conditions. 


\section{Literature Cited}

Cao, X.W., G. Zang, L.J. Meng, P. Xiao, S.B. Chen and S.L. Chen. 2009. Alkaloid constituents of Fritillaria cirrhosa. Chinese Traditional and Herbal Drugs 40(1):15-17.

Chao, R.B. and L. Hu. 1993. Study on analysis of blubs Fritillariae by HPLC. Acta Pharm Sin 28(9):705-708.

Chen, M.H., H.C. Wang, Y.M. Zhu and Z. Chen. 2007. Pharmacological research on Fritillaria. Anhui Agri. Sci. Bull 13(1):103-105.

Gao, S.L., Y. Xia and F.P. Tan. 2000. The pharmacological action of cultured bulb of Fritillaria unibracteata Hsiao et K. C. Hsia. Plant Res. Environ. 9(1):4-8.

Hua, R., S.Q. Sun, Q. Zhou, I. Noda and B.Q. Wang. 2003. Discrimination of fritillary according to geographical origin with flourier transform infrared spectroscopy and twodimensional correlation IR spectroscopy. J. Pharmaceut. Biomed. Anal. 33:199.

Hua, Y.U., J. Yan, P. Li, S.P. Li and Y.T. Wang. 2005. Study on analytical method for alkaloids in bulbs Fritillariae cirrhosae. China J. Chinese Materia Medica 30(8):573-575.

Li, A.R. 1995. A review on the study of Fritillaria anhuiensis. China Tradit. Herb Drug 26(4):218.

Li, S.L., G. Lin, S.W. Chan and P. Li. 2001. Determination of the major isosteroidal in bulbs of Fritillaria by high-perfomrance liquid chromatography coupled with evaporative light scattering detection. Chromatography A 909:207-214.

Lin, G., P. Li, S.L. Li, and S.W. Chan. 2001. Chromatographic analysis of Fritillaria isosteroidal alkaloids, the active ingredients of Beimu, the antitussive traditional Chinese medicinal herb. Chromatography A 35:321.

Pi, H.F. and J.Z. Wu. 2004. Study progress about the new resources of Fritillaria plant from 1980. Nat. Prod. Res. Dev. 16(4):336-371.

Wang, S., X.P. Xu and L. Tao. 2002. Determination and contrastion of alkaloids and saponins in bulbs Fritillariae Cirrhosae and in other Beimus. China J. Chinese Materia Medica 27(5): 342-344.

Xiao, P.G., Y. Jiang, P. Li, Y.B. Luo and Y. Liu. 2007. The botanical origin and pharmacophylogenetic treatment of Chinese material medica Beimu. Acta Phytotax on Sin 45(4): 473-487.

Zhang, J.L., H.F. Pi, H.L. R, Y.H. Zhang and J.Z. Wu. 2007. Studies on non-alkaloid constituents from the stem and leaf of Fritillaria hupehensis. China J. Chinese medicine 26(1): 23-24.

Zhou, J.X., L. Kang, J.B. Bi and Z.W. Shen. 2006. The safety discussion of use bulbs Fritillariae in traditional Chinese medicine and functional foods. SH. J. TCM 40(4):66-67.

(Received 24 June 2011 ; Revised 20 December 2011 ; Accepted 28 December 2011) 